\title{
Linkedin As A Learning Tool In Business Education
}

\author{
Brett Cooper, Saint Peter's University, USA
}

Mary Kate Naatus, Saint Peter's University, USA

\begin{abstract}
This article summarizes the existing research on social media as a learning tool in higher education and adds to the literature on incorporating social media tools into collegiate business education by suggesting specific course content areas of business where LinkedIn exercises and training can be incorporated. LinkedIn as a classroom tool cannot only reinforce basic concepts, such as branding and relationship-building, but creative use of this tool can increase student engagement and collaboration and encourage students to begin building their professional networks, which can be vital in their career progression.
\end{abstract}

Keywords: LinkedIn; Social Networks; Business Education; Classroom Technology

\section{INTRODUCTION}

( $\mathrm{n}$ today's university environment, there is a lively debate about the use of social media in the classroom. Some faculty forbids the use of smart phones, tablets and computers in class, as they can cause students to be distracted and off task. Others are incorporating mobile devices and social media into class activities and class discussion, particularly in certain disciplines such as marketing and communications. One professional social network that is thriving and attracting business professionals from around the world is LinkedIn and, as a social network, it is beginning to rival Facebook and Twitter in terms of content sharing and engagement. This professional-oriented social network allows users direct networking access to decision-makers and can allow business students and young job applicants to reach out directly to managers rather than going through a gatekeeper in Human Resources. Once you are linked, you are given the contact's direct email address and also have the option to send a message directly through LinkedIn. As the job market continues to be competitive and it becomes more difficult for college students and recent graduates to differentiate themselves from other job-seekers, networking tools like LinkedIn can be a key component for them to build their professional networks, enhance their credentials and increase their social capital. While today's college students are adept at using social media in a casual context, Wankel (2010) notes that the development of professional proficiency by students to use social media to meet business objectives, would be an invaluable tool for business graduates entering the workforce. Incorporating social media into business courses is an emerging topic that is beginning to be explored in the field of business education (Albrecht, 2011; Liu, 2010), but more exploration is called for in this area.

The purpose of this article is to explore the limited studies that have been done on using social media in the college classroom, to suggest some ways of incorporating LinkedIn as a tool in various business courses, and to address the issue of helping students to develop a professional online identity and brand and be aware of the impression they are creating in a very public forum through their online activity. Further, the authors will discuss specific business skills and concepts, which can be augmented and applied through the incorporation of social media, and specifically LinkedIn, as a teaching tool in the classroom.

\section{Social Networks In The Classroom Environment}

By definition, Social Networking software can be defined as "web-based services that allow individuals to (1) construct a public or semi-public profile within a bounded system, (2) articulate a list of other users with whom they share a connection, and (3) view and traverse their list of connections and those made by others within the 
system" (Boyd \& Ellison, 2008). On the other hand, social networking sites have been described as "relationship facilitators" (Educause, 2007) allowing individuals to construct relationships with other individuals with similar attentiveness and interests. In effect, SN technologies create an active sense of community. A 2010 study (Junco, Heiberger, and Loken) that used an experimental approach with a control group, found that students engaged in communicating on assignments outside of class via Twitter "had a significantly greater increase in engagement than the control group, as well as higher semester grade point averages", providing some evidence of the potential of social networks for enhanced communication and engagement.

According to USA Today writer, Jonathan Dane (2013), there has been a significant increase in the number of college faculty members that are using social media as a teaching tool. An October 2013 survey, conducted jointly by Pearson Learning Solutions and Babson Survey Research Group of over 8,000 faculty members, found that $41 \%$ of college professors use social media as a teaching tool, up from around $34 \%$ the previous year. When one considers the changing educational landscape with the rise of MOOC's and all of the free content that is available to students, traditional colleges and universities must continue to differentiate the educational services provided to students, especially with rising tuition costs and the looming student debt crisis (Johnson et. al., 2013). Another study (Fidelman, 2012) found that very few MBA programs have courses specifically on social media, which some experts believe demonstrates an outdated approach that overlooks the significant impact that these media have had on the buyer/seller relationship and on re-shaping traditional business models. Incorporating professional tools like LinkedIn into the classroom environment can help business school faculty increase the level of student engagement and build career preparation into a variety of business courses and, at the same time, be used as a discussion tool to address these changes in the business environment. As Rodriguez (2011) notes in her research on this topic, while faculty are embracing the use of new and innovative technologies in the classroom, the process is more like a grassroots movement than a carefully planned and institutional initiative. In addition, if faculty document and share their ideas, mistakes, success stories and empirical findings, business educators can collectively improve the incorporation of social media tools into the curriculum.

\section{Why LinkedIn?}

LinkedIn has become one of the most popular and profitable social networking sites on the internet today. It was created in 2003 as a networking site for professionals to connect virtually, without having to be in the same physical location. Since going public in May 2011, LinkedIn has incorporated many new features, such as a newsfeed, user content, and the ability to follow professionals, improving user engagement and time spent on the site. The network currently has over 260 million users in over 200 countries (Smith, 2014). LinkedIn has many capabilities that facilitate the type of networking that college students must engage in to find internships, jobs and make professional connections. Users post an equivalent to a resume on the site, including specific skills they possess. The website uses statistical techniques to connect or link users with potential contacts and relevant groups (Albrecht, 2011). A new feature of the site is the original content generated by high profile business leaders, called "Infuencers", such as Richard Branson, Bill Gates and Ariana Huffington.

Unlike on Facebook and other social media sites, LinkedIn users can feel comfortable linking to people who are casual acquaintances or new contacts and not worry about people viewing personal information or personal pictures, aside from a profile picture, since these are not the type of content users post on the site. From a branding perspective, LinkedIn offers users the opportunity to create a professional profile and sculpt it in a manner that is attractive to employers and also take advantage of endorsements and recommendations by colleagues, professors and supervisors. Unlike a resume, formatting is never an issue because LinkedIn uses forms that the user can fill out and then post to one's profile with a standard format.

A public profile is viewable by potential employers, connections, colleagues and other students. Recruiters are now using LinkedIn to recruit and review qualified candidates, and users can apply to jobs through LinkedIn, streamlining the traditional processes. The more connections and the bigger your network is, the better chance that a connection is in a position to help you find your next job or grow your career. Many companies have LinkedIn profiles with valuable information on the company which is important when you get an interview. This is a good place to find out what the company is doing in the news, see where their offices are located, the number of employees, the industries they are in, jobs they are hiring for, and other valuable information - all in one place. Also, 
since the information is posted directly by the company, viewers know it is accurate and up to date. Linkedin's filters allow users to identify the companies where members of their network are working, which can be very useful in facilitating referrals and making introductions. You can easily target people in and out of your network that work for a company that you wish to intern or work for. It is always better to get your resume into someone's hand that can make sure your resume gets to the right person and is noticed. Also, if your contact knows you he/she can put in a good word and act as your advocate for getting the position. A direct referral is a more effective way of getting a job than applying through a company's website to a generic mailbox that may get hundreds of resumes a day.

You can easily target people in and out of your network that work for a company you wish to intern or work for. It is always better to get your resume into someone's hand that can make sure your resume gets to the right person and gets noticed. Also, if your contact knows you, he/she can put in a good word and act as your advocate for getting the position. A direct referral is a more effective way of getting a job than applying through a company's website to a generic mailbox that may get hundreds of resumes a day.

In most Google searches, a person's LinkedIn profile comes up at the top of the search, which is significant for students in terms of their own branding and SEO (Search Engine Optimization). This helps push other items down the page, such as other social media pages or web posts that may not be as favorable from a professional standpoint. If your LinkedIn profile comes up first, this gives a good first impression and it is always important to make a good first impression. By incorporating a LinkedIn workshop into Marketing and Business classes and encouraging students to proactively create their online professional identity using this social network as a tool, it makes them more conscious of the importance of cultivating a positive brand image and communicating in a professional manner.

When creating professional profiles on LinkedIn, students are free to include valuable experience that might not fit on the recommended one-page traditional resume. LinkedIn allows users to easily add many organizations, job titles and skills acquired, and it calculates the amount of time spent at each job, including sending newsfeed messages to users when they reach a work anniversary. A user can also give full job descriptions and include all projects worked on or any other significant details. The key to getting your resume noticed, especially when submitting through an online application portal, is making a connection with the reviewer. This can be done by having something in common, like a college attended or a common place of employment. Since LinkedIn profiles allow for unlimited amount of jobs and details, it increases the probability of making connections with the reviewers and other individuals with influence on hiring decisions.

The more connections and endorsements a user has, the more valuable a candidate appears to current and future employers. It can serve as validation and confirmation of the person's background. In certain careers like sales, a large LinkedIn network can be particularly valuable in terms of establishing leads and creating revenuedriving relationships, as each connection is a potential client.

Since LinkedIn has become the premier social media site for professionals, most employers will search for a job candidate on LinkedIn, and it might actually leave a negative impression if a job candidate does not have a LinkedIn profile. In this digital age, business students and graduates do not want to appear behind the times and have it be a first impression. In addition, a recent Pearson study on this topic (Seaman \& Tinti-Kane, 2013) found that LinkedIn is the most commonly used social network by university faculty,

\section{Strategies For Effective Classroom Use Of Linkedin}

While the explanations above provide evidence on why job-seekers, students and professionals should be using LinkedIn, this may not be enough to convince faculty members, who have limited time and resources to cover required core concepts in their classes, to add this as a module in existing courses or to create a new social media business-oriented course. Therefore, it would be helpful to identify key content areas in typical business and marketing courses, where a discussion and workshop on LinkedIn fits in seamlessly and can be used to enhance or illustrate the same concepts that need to be covered. In addition to reinforcing learning outcomes, LinkedIn and other social networking tools can be used to increase student engagement and collaboration during the class and beyond (Stewart \& Grover, 2010) since LinkedIn connections are never more than a click away. 


\section{Branding}

It is clear from the competitive job market that business students need to work on their personal brand and how they market themselves to potential employers (Donnelly, 2013).LinkedIn helps students form and strengthen their personal brand and allows them to shape the message they are sending in any way they wish. LinkedIn allows students to highlight key areas of education or experience to potential employers in the field they wish to work. Businesses should also look at branding on LinkedIn similar to how students do. Businesses are not only creating their brand to potential consumers, but also to business partners who are on LinkedIn, as well potential employees. When a Google search is performed on an individual or a company, one of the first search results is their profile on LinkedIn. Additionally, when potential employees research a company that they wish to apply to or eventually work for, they do research on LinkedIn. Therefore, the companies with the strongest brand and most information on their LinkedIn page will attract the most candidates. The largest pool then optimizes the likelihood of locating the most qualified candidates. A strong brand on LinkedIn can help the company reduce human resource costs and help the bottom line by attracting the best candidates.

A strong LinkedIn brand can also help attract and strengthen partnerships with other organizations. Companies can research potential or current partners and see the strength of their network. A larger network makes the relationship more valuable to future partners by offering more outlets to advertise the new partnership, which leads to more introductions to future partners. Having all current employees active on LinkedIn helps strengthen the public brand image, leading to more partnerships and ultimately, more profits. In teaching a basic marketing class, branding is an important part of product strategy. An exercise on personal branding via LinkedIn can easily be incorporated into lower-level marketing classes. Students can be encouraged to seek LinkedIn recommendations and endorsements to help build their brand equity on the site. Using some of the strategies in Shaffer's (2009) book on creating and implementing your LinkedIn brand, students can learn and apply the principles of branding to their LinkedIn page and identity, and even incorporate the basics of keyword and SEO, which Shaffer emphasizes as important in differentiating your LinkedIn brand. After the initial LinkedIn introductory exercise incorporating branding, students can learn on their own and be as engaged as they like on the site, but it does not have to take up additional class time.

\section{Market Research}

LinkedIn is a vast source of data for market research. Through their email system, you can quickly reach out to targeted members of a certain industry and get feedback on a new product, service or marketing campaign. LinkedIn allows you to reach a very targeted sample pool of professionals and the principal investigator can be fairly confident that all the feedback received is from informed people, like executives and managers in the targeted industry. Companies, such as Cathay Pacific and Jaguar South Africa, have successfully used LinkedIn as a marketing research tool to target business executives and potential customers in the promotion and repositioning processes (LinkedIn Marketing Solutions Webpage). When discussing the marketing research process, including the dissemination of surveys to a sample of respondents, a professor could compare LinkedIn to other social media outlets, such as Facebook and Instagram, in terms of the profile of individuals who could best be targeted through each medium. Social media is constantly changing, so new information is available minute by minute. Status updates are a good way to see what companies are growing and who in your network has changed positions or companies. A lot of corporate news is first revealed through LinkedIn allowing you to have first-hand knowledge straight from the newsmaker, with no media distortion. Through LinkedIn's groups, you can brainstorm ideas and connect with others who may have the same questions or may have already done the research you need and would be happy to share. LinkedIn is an under-used tool to save time and money in the area of market research.

\section{Relationship Building}

Since LinkedIn is a social media website, one of its main functions is relationship building and encouraging connections among users and content sharing. LinkedIn allows each user to build a network that is focused primarily on professional connections, which differentiates it from other sites like Facebook and Instagram. LinkedIn facilitates this by "suggesting" possible connections that have similar work and educational backgrounds or connections in common. A new feature on the site makes suggestions on how to increase your network by a 
certain percentage, which can include the recommendation to share a specific news-related article, follow a specific "Influencer" or connect with another specific user. All direct link requests are vetted by the site and users cannot request a direct link without stating how one knows that person.

Once the network is built and the website recommends a minimum of 50 contacts for the potential benefits to be leveraged, users can search their contacts filtering by companies, industries, schools or other keywords, making it easy to identify connections who might have influence in a certain area or to make an introduction to someone outside of your network. In an essay published as a book chapter (2012), Tinti-Kane et al. note how social media in the higher education classroom, when used appropriately, can enhance the communication process and allow students to connect with experts on topics of interest or subjects they are researching. They can participate in relevant conversations on LinkedIn through Groups and the Influencers' newsfeed and also observe how others are weighing in on topics of interest. The authors recommend emphasizing to students that while useful, LinkedIn is a tool, and that face-to-face contact and other more personal forms of communication are also vitally important in cementing and sustaining relationships.

\section{Sales}

Sales is another area where LinkedIn can have a big impact. The professional global network of over 250 million people is a great opportunity for salespeople to identify potential buyers, clients and customers. LinkedIn introductions have, to some degree, replaced the cold call and often lead to a better response. Sales professionals are able to search their network and find a common link to use as an icebreaker in the sales process. The information available about potential clients on LinkedIn allows the sales pitch to be tailored to the needs of the client from the start and often minimizes the amount of questions that can take up valuable time. LinkedIn allows a sales professional to review companies that could potentially use their product or service and look for employees they know or have something in common and use this link as a way into the organization. As noted above, sales professionals can use their existing network as a valuable source or potential introductions to thousands of professionals in their extended network. A LinkedIn profile can serve to legitimize a professional, should a potential client research the salesperson or the salesperson's company before dealing with them. Their profile can be developed to highlight their experience in the industry or with a particular product. Finally, a relationship can grow and be strengthened through LinkedIn in a user-friendly environment, with reduced geographic and cultural barriers due to a common language and format within the LinkedIn Network.

\section{Business Communications}

A final content area that will be highlighted in this article, which is a component of all business programs, is professional communication. LinkedIn groups are a great way to communicate with a select group of professionals inside and outside of an organization. These groups allow professionals with a common interest or an organization in common to communicate in a language that all members would comprehend. These groups also allow a forum to discuss ideas for products, marketing campaigns or just general information for upcoming meetings. Outside vendors and clients can also be included to allow feedback and market research. Organizations can also use company pages to communicate new product information, recall notices, or solicit feedback from users. These pages allow the company to control the message in a professional setting where the users viewing their page are all professionals with some link or interest in what the organization has to say and has sought out this information. LinkedIn has also added many features in recent years making it more like a media company, allowing longer form content creation on business-related topics, so students with an interest in marketing and communication can create relevant content and share easily with followers and others on the site.

A drawback noted in the literature on incorporating social media into collegiate business education is the lack of proper development of the communication skills required in the global marketplace (Okoro, 2012). With creativity and planning, LinkedIn can be used as a platform to encourage improvement of business communication skills. Professors can consider assigning students to write a short, concise and interesting article to be published on the student's LinkedIn page instead of submitted in a more traditional manner. Grading and feedback from the professor would be useful before final posting, but encouraging this type of professional postings by students would not only help them to apply course concepts and terms, but also create a more robust professional profile and possibly even a following on LinkedIn. 


\section{CONCLUSION}

There is no doubt that LinkedIn is a fast growing global professional network that can be a valuable tool for business people and students, whether or not they are actively seeking a job. With two new users joining the network every second (Conner, 2013), a presence in over 200 countries, and a reputation as one of the most successful startups in recent years, it makes sense that business faculty discuss LinkedIn in their classrooms. By familiarizing students with LinkedIn and encouraging them to create strong professional profiles, it can help students differentiate and market themselves and grow their networks, which is a must in today's competitive job environment. This alone may not persuade professors to use LinkedIn in the classroom, which is why this article emphasizes how LinkedIn can also be used to help elaborate on business and marketing topics and concepts to easily fit it into the course syllabus. Going forward, the authors plan to create a LinkedIn group for business educators, in addition to a blog, in order to share best practices and teaching tips on incorporating social media tools and LinkedIn into college-level courses. In addition, more empirical studies using survey data or outcomes-related data would be useful to measure the actual and perceived impacts of LinkedIn use over time for students during and following their time in school.

\section{AUTHOR INFORMATION}

Brett A. Cooper, JD MBA, is a Lecturer of Business at Saint Peter's University in Jersey City, New Jersey. He has over ten years of college teaching experience in the areas of law, sports management and economics Prior to Saint Peter's University, he has taught at the undergraduate level at N.J.I.T., Wilmington University, Centenary College, Northampton Community College, and American Centennial University, and on the graduate level at Rutgers University, Franklin Pierce University, and Fairleigh Dickinson University. Brett has also taught over 75 classes on Legal Basics for small business owners through the New Jersey Self Employment Assistance Program. He is licensed to practice law in New Jersey and the Federal Courts of the Third District and has been practicing in numerous legal areas with a concentration on business law for over 12 years. Brett earned his J.D. from Rutgers Law School in Camden, NJ, his M.B.A. from Rutgers Business School in Camden, NJ, and a B.A. in Sports Management and Communications from University of Michigan in Ann Arbor, MI. His research interests social media, networking, legal issues in the sports industry, and entrepreneurship. Brett is in the top $1 \%$ of all people on LinkedIn, based on the number of links with over 2,700 connections, which gives him access to over 17 million professionals. His profile on LinkedIn has a top rating of All-Star.

Mary Kate Naatus, PhD, MBA, is an Assistant Professor of Business at Saint Peter's University. She has ten years of college teaching experience in business disciplines, including international business immersion courses involving foreign travel. Prior to Saint Peter's, she worked in academic program management and marketing at NJIT. Mary Kate spent two years working in international development for the Peace Corps in El Salvador, where she was awarded grant funding through USAID and a Spanish NGO for several infrastructure projects. She has also worked for Bestfoods International (now Unilever), La Casa de Don Pedro, a non-profit organization in Newark, NJ, and HR Plus, a human resources consulting firm. She received her Ph.D. from Rutgers in Global Affairs, an MBA in Management from NJIT, and a B.A. in Journalism from The College of New Jersey. Her research interests include international business and culture, urban entrepreneurship, and mobile and digital marketing.

\section{REFERENCES}

1. Albrecht, W. D. (2011). LinkedIn for Accounting and Business Students. American Journal of Business Education, 4(10) 39-41.

2. Boyd D. \& Ellison, N. (2007). Social Network Sites: Definition, History \& Scholarship. Journal of Computer-Mediated Communication. 13(1).

3. Dane, J. (2014, November 4). More Professors using social media to teach. USA Today.

4. $\quad$ Donnelly, R. \& Rhoad, T. (2013). Personal Brand Planning for Life. BT Consulting.

5. Conner, C. (2013, October 27). Five LinkedIn strategies you haven't thought of before. Forbes. Retrieved from http://www.forbes.com/sites/cherylsnappconner/2013/10/27/five-linkedin-strategies-you-havent thought-of-before/.Fidelman, M. Guess how many top 25 business schools don't teach social media business? 4/25/12 Forbes. 
6. Johnson, L., Adams Becker, S., Cummins, M., Estrada, V., Freeman, A., and Ludgate, H. (2013). NMC

Horizon Report: 2013 Higher Education Edition. Austin, Texas: The New Media Consortium.

7. Okoro, E. (2012). Integrating social media technologies in higher education: Costs-benefits analysis. Journal of International Education Research, 8(3), 255. Retrieved from http://search.proquest.com/docview/1433379372?accountid=28700.

8. Rodriguez, J. (2011). Social Media Use in Higher Education. Merlot Journal of Online Teaching \& Learning. 7(4)539-550.

9. Shaffer, N. (2009). Windmill Networking: An unofficial, step-by-step guide to creating and implementing your LinkedIn brand. BookSurge Publishing.

10. Smith, C. By the numbers, 80 Amazing LinkedIn Statistics. DMR. Feb. 9, 2014. Retrieved from http://expandedramblings.com/index.php/by-the-numbers-a-few-important-linkedinstats/\#.U2DYoK1dU1s.

11. Stewart, A. \& Grover, D. (2010). Defining Interactive Social Media in an Educational Context. In C. Wankel \& M. Marovich \& J. Stanaityte (Eds.), Cutting edge social media approaches to business education: Teaching with LinkedIN, Facebook, Twitter, Second Life, and Blogs (pp. 7-38). Charlotte, NC: Information Age Publishing.

12. Seaman, J. Tinti-Kane, H. (2013). Social media for Teaching and Learning. Pearson Education. Retrieved from http://dev.pearsonlearningsolutions.com/assets/downloads/reports/social-media-for-teaching-andlearning-2013-report.pdf.

13. Wankel, C. Technologies That Bring Learners Collaboratively Together With the World. Technologies that bring learners collaboratively together in the world. In C. Wankel \& M. Marovich \& J. Stanaityte (Eds.), Cutting edge social media approaches to business education: Teaching with LinkedIN, Facebook, Twitter, Second Life, and Blogs (pp. 1-6). Charlotte, NC: Information Age Publishing. 
NOTES 